\title{
Research on the System of Fiscal Transfer Payment from the Perspective of Equalization of Basic Public Services
}

\author{
Dingqiang DUAN \& Jing ZHOU \\ Wuhan Textile University, Wuhan, China
}

\begin{abstract}
Achieve the equalization of public services must rely on fiscal transfer payment. China's transfer payment system has some defects such as the size of general transfer payments is too small, Transfer payment system has significant revenue sharing features and has significant inverse equalization effect. China's government should learn from the western developed countries and reform the transfer payment system in order to prompt the equalization of public services, make a clear division of governments' responsibilities, formulate a law and make good use of the horizontal transfer payment may be some good suggestions for China's government.
\end{abstract}

KEYWORD: Transfer payment; Equalization; Public services

\section{INTRODUCTION}

In order to achieve the goal of sharing the fruits of reform and development, the Chinese government has been paying attention to promote the equalization of basic public services, but still faces many challenges now, not all the basic public services has been equalized, and there are even some deterioration in some aspects. As an effective mean which can balance regional financial capacity, intergovernmental fiscal transfer payment system should have played a greater role in promoting the equalization of public service. But at present, China's fiscal transfer payment system is just a system tool to solve uneven financial distribution between the central government and the local government, plays a limited role in soluting horizontal financial imbalances among regions on and it is helpless to further promote the equalization of public services. Therefore, it is necessary to learn the experiences from other countries, reform China's transfer payment system, and realize the equalization of public service.

\section{THE THEORETICAL FOUNDATION OF ACHIEVING THE EQUALIZATION OF PUBLIC SERVICES THROUGH TRANSFER PAYMENT}

Many theories, including the Theory of Welfare Economics and Theory of Public Finance, have proved that the equalization of public services are closely related to the transfer payment system.

\subsection{Theory of Welfare Economics}

Theory of Welfare Economics points out that the allocation of public service has a great influence on the distribution of national income, and equalization of public services is helpful to maximize the welfare of the whole society. According to the theory of welfare economics, the equalization of public services is the inevitable requirement of the social welfare maximization, fiscal transfer payment system can promote the equalization of public services.

\subsection{Theory of Public Finance}

The basic function of public finance is to make up for the market failure, supply the public products and services which can't supply through market mechanism. The equalization of public services is an important goal of public finance. Fiscal transfer payment system is the most important means for government to regulation public capacity, its scale and structure directly affects the degree of realization of regional equalization of public service. That means better fiscal transfer payment system can accelerate the equalization of public services. 


\subsection{Kaldor compensation principle}

The principle of compensation is concerned with "the welfare of the whole society", and it is another theory which supports that we can achieve the equalization of public services through transfer payments. Transfer payment is used to solve the unequal distribution public services brought by the unbalanced development of regional economic, the transfer payment will change change the financial distribution among local governments, some regions' social welfare may be reduced and some other regions' may increase, but the social welfare will increase on the whole. Therefore, the transfer payment can improve the regional equalization of public service, which can increase the "welfare of the whole society".

\section{SOME EXISTING PROBLEMS ABOUT CHINA'S TRANSFER PAYMENT SYSTEM IN PROMOTING EQUALIZATION OF PUBLIC SERVICE}

\subsection{The defects of China's transfer payment system in promoting equalization of public service}

\subsubsection{The size of general transfer payments is too small}

In our country's financial transfer payment system, tax rebates and special subsidies are the main means of adjusting financial resources between governments. First, the tax rebates accounted for $40 \%$ of total transfer payment. Because of the unreasonable base of tax rebates, underdeveloped regions can only get a less amount of tax return. Second, special subsidies accounted for about $30 \%$ of the transfer payment, but the special subsidy range is too wide, covering almost all the subjects of budget expenditure, and lacks strict system restriction, the use of funds is dispersed and not efficient. So it is not helpful for the equalization of public services, and it will aggravate the imbalance of local financial resources. Third, at present, it is the general transfer payments that can really promotes the equalization of public services, but due to the small size, it is still very limited to balance the regional financial and realize the equalization of public service.

\subsubsection{Transfer payment system has significant revenue sharing features}

Our country's current financial transfer payment system is established along with the tax sharing system reform in 1994, there was not normative transfer payment system before that, and revenue sharing is the main goal of financial transfer payment in the traditional financial system. Although the reform of tax system in 1994 admitted the existing distribution pattern between the central government and local government, established transfer payment system with tax rebates and subsides as the main form, but still remained the financial distribution pattern, the problem of uneven distribution financial resources between regions has been not changed, and the gap of public service among regions was not reduced either.

\subsubsection{Significant inverse equalization effect}

First, the existing tax return system causes that tax rebates amount of developed area is high and the amount of tax rebates in poor area is low, that means the financial gap between regions is reverse regulated. Second, the special subsidy usually requires local governments provide matching funds. Developed areas have the resources to provide matching funds, thus obtaining a large number of special subsidies. While the underdeveloped regions cannot obtain the special subsidy due to inability to provide matching funds. Thus the imbalance between the local financial resources has been exacerbated.

\subsection{Reasons for the insufficiency of transfer payment system}

\subsubsection{Current transfer payment system has not clear policy objectives for equalization of public services.}

In China's current transfer payment system, in addition to the special funding, the rest forms are general grant projects. But only transitional transfer payment is designed for the objectives of equalization, and the target of other transfer payment forms are not clear. Among them, tax rebates are no difference for all the regions, so it is not associated with the goal of equalization. The policy goal special subsidy should be supplying public service which has spillover benefits, such as basic education, cross regional roads, water conservancy facilities, but at present, our country's special subsidy involves almost all expenditure items, expenditure responsibilities between central government and local governments have not been divided clearly, the phenomenon of offside and absence are coexistent.

\subsubsection{The structure of financial transfer payment is not reasonable}

Tax rebates occupy a larger proportion of China's fiscal transfer payment. But tax rebates is used to ensure vested interests of local governments and usually tilt toward the area with strong income ability, regardless of the equalization of public services, that results in insufficient fiscal ability in many western regions. In other words, tax rebates maintain and cure the original unreasonable interest distribution pattern, gradually widened the gap among regions. Due to the lack of scientific basis, 
there are great arbitrariness in the division of financial subsidies, that often cause bargain between different level governments and it is obviously unfair. At the same time, Earmarks often become a tool for local governments to balance their finance due to the lack of supervision.

\subsubsection{The allocation of transfer payment funds is lack of quantitative basis}

Our country's current financial transfer payment system has not established a set of scientific and perfect calculation formula, so the distribution of funds is lack of scientific basis. At present, the main calculation method is the "base" method, the base is approved according to the revenue base of local governments in 1993, so, to a great extent, it is a continuation of the allocation methods of that time, weakening of the allocation function and regulating function of fiscal transfer payment, deviating the goal of the equalization of public service.

\section{FOREIGN EXPERIENCES IN REFORM FINANCIAL TRANSFER PAYMENT SYSTEM FOR THE PURPOSE OF THE EQUALIZATION OF BASIC PUBLIC SERVICES}

Because of unbalanced development of regional economy, almost all governments of the world achieve fiscal balance between regions through fiscal transfer payment.

\subsection{Germany}

In Germany, horizontal and vertical transfer payment is both used to regulate financial resources between different governments, in which the horizontal transfer payment's function of equalization is more obvious. The transfer payment system in Germany takes providing the same or similar levels of public services to the national residents as its fundamental target. In determining the amount of transfer payment, considering only the equalization of regional fiscal capacity but not the differences of expenditure needs between regions. So it can not only narrow the regional gap and guarantee to provide roughly the same public services ,but also promote the development of the national economy.

\subsection{Japan}

In Japan, transfer payment system does not apply a particular subsidy method, but uses the subsides with prescribed purposes and no prescribed purposes, subsides with additional conditions and no additional conditions. In general, the central government use subsides without prescribed purposes and additional conditions for the purpose of increasing the fiscal capacity of low income areas, in order to strengthen local capacity of supplying one or several kinds of public goods, the special subsidies with additional conditions are more used. Usually, general grant is the main way of implementing regional fiscal revenue coordinate, and the special subsidy is conducive to achieve the efficiency goal, improving the levels of supplying public products.

\subsection{Canada}

The difference of the fiscal capacity in different regions of Canada is relatively large, so the transfer payment was introduced to Canada very early. The distribution of transfer payment in Canada is decided by calculation formula. When calculate, the fiscal revenue ability of every province should be calculated firstly, without consideration of the actual fiscal revenue. Canadian transfer payment is a federal legal expense, Congress has to give a new authorization approval every five years, to ensure the transfer payment can be distributed by the most equal program and serve for the equalization of public services.

\section{SOME SUGGESTIONS ON THE REFORM OF CHINA'S FINANCIAL TRANSFER PAYMENT SYSTEM}

\subsection{Make a clear division of expenditure responsibilities at all levels of governments}

Under the system of market economy, the expenditure responsibilities of the governments should be regulating according to the level of public goods. The national public goods should be provide by the central government and local public goods should be provided by the local government. Then we should speed up the pace of transformation of government functions at all levels, ensure its main function is to provide public services, determine the number of transfer payment according to the scope of government authority.

\subsection{Formulate "the fiscal transfer payment law"}

Lots of developed countries in the world constrain fiscal transfer payment with law, therefore, we suggest that our government to learn from the experience of developed countries on the fiscal transfer payment, regulate the content, specific uses, form of supervision and punishment rules of fiscal transfer payment system in the form of legislation. 


\subsection{Increase the proportion of general transfer payment}

To reduce the financial differences between regions, the scale and proportion of general transfer payment must be enlarged. We have two alternative approaches: the first is based on the amount of existing general transfer payment, increase by a fixed amount year by year. The second is determining the scale according to the provincial proportion which can be used by transfer payment. Relatively speaking, the second method is more flexible, the more public resources centralized by provincial finance, its macro-control ability is stronger, and the efforts to equalize regional financial resource is stronger.

\subsection{Try the new mode of the combination of vertical transfer payment and horizontal transfer payment}

The gap between the eastern and western regions of China is too large and the financial resources of central government are very limited, it is very difficult to achieve the equalization of public services if just relying on a central longitudinal transfer to local. In fact, there has been a political and ideological basis for the eastern developed provinces of China to support Western undeveloped provinces, such as the targeted aid to Tibet and
Qinghai by eastern developed provinces, but there is not a mature system. At present, the level of China's eastern region's economic development has been close to the level of some developed countries, the eastern provinces have had the conditions, also had the duty to support the development of underdeveloped areas. Therefore, coordinating the financial resources between the eastern and western regions with horizontal transfer payment, can form an effective supplement of vertical transfer payment, and promote the equalization of public service supply among regions.

\section{REFERENCES}

[1] Wang Ying: Fiscal Equalization Theory and Practice. Chinese financial and Economic Publishing House, 2008

[2] Chi Fulin: Straightening out Relations Urged the Public Service Equalization. China Reform Newspaper, 2007

[3] Ma Guoxian: Research on the Public Finance Policy about Equalization of Basic Public Services. Finance research, 2007.

[4] Guan Yonghao, Hong Liang: The Equalization of Basic Public Services: the Present Situation, Evaluation of Domestic Research. JAC Forum, 2008

[5] Wang Yong: Realizing the Equalization of Basic Public Services: Responsibility and Countermeasures of Finance. Finance research, 2008

[6] Zhang Qichun: Regional Equalization of Basic Public Services and Government Transfer Payment. Journal of Huazhong Normal University, 2009. 